\title{
ESTRUTURAS E CARACTERÍSTICAS DE VEÍCULOS HÍBRIDOS E ELÉCTRICOS
}

RESUMO

Nas últimas décadas tem-se assistido a um forte desenvolvimento dos veículos eléctricos, sobretudo das soluções híbridas, como resposta aos impactos ambientais $e$ económicos dos combustíveis fósseis. Os desafios que se colocam no campo da engenharia são múltiplos e exigentes, motivados pela necessidade de integrar diversas áreas, tais como, novos materiais e concepções de motores eléctricos, electrónica de potência, sistemas de controlo e sistemas de armazenamento de energia.

Neste artigo procura-se apresentar as principais características dos veículos híbridos eléctricos (VH) e dos veículos puramente eléctricos (VE).

Começa-se por uma breve referência à origem e evolução destes veículos. Segue-se uma abordagem às diferentes configurações de VH e VE - principalmente no que se refere aos sistemas de propulsão e armazenamento de energia -, realçando as suas vantagens e desvantagens. Por fim, referem-se alguns dos factores mais relevantes para a evolução tecnológica e aceitação destes veículos.

\section{INTRODUÇão}

Os conceitos de veículo eléctrico e híbrido eléctrico remontam às origens do desenvolvimento do próprio automóvel, em finais do séc. XIX. Numa época onde as preocupações ambientais e de eficiência não existiam, a finalidade era incrementar os níveis de desempenho dos motores de combustão interna $(\mathrm{MCl})$ ou melhorar a autonomia dos veículos baseados em motores eléctricos. Com efeito, o desenvolvimento destes motores encontravase ainda numa fase inicial, estando a tecnologia associada às máquinas eléctricas num nível superior. É nesta época que se regista a implementação de sistemas de frenagem regenerativa, que permitem recuperar a energia cinética que o veículo perde, em consequência de uma travagem, sendo armazenada nas baterias. Trata-se de uma contribuição fundamental para a eficiência destes veículos e respectiva autonomia - questão determinante para o desenvolvimento dos veículos eléctricos [1].

A partir da década de 1920, a enorme evolução verificada nos motores a gasolina (principalmente, no aumento da potência disponível e rendimento, com menores dimensões) tornou-os preponderantes face aos motores eléctricos. A maior dificuldade no seu controlo (baseado em contactos mecânicos e resistências, com baixos níveis de eficácia, comprometendo o próprio desempenho do veículo), a reduzida autonomia, peso e custo mais elevados, são os principais motivos que explicam aquela supremacia [1].

As crises energéticas ocorridas na década de 1970 e o aumento das preocupações ambientais (principalmente nas sociedades ocidentais), juntamente como desenvolvimento da electrónica de potência, que permitiu a criação de sistemas eficazes de controlo de motores eléctricos, despertaram interesse para o desenvolvimento de veículos puramente eléctricos, de que é exemplo a grande quantidade de protótipos construídos na década de 1980 .

Na década de 1990 as concepções híbridas foram ganhando interesse, face à tomada de consciência das dificuldades em superar as limitações dos veículos eléctricos, relativamente aos veículos convencionais com $\mathrm{MCl}$. Nesse sentido, vários fabricantes de automóveis desenvolveram diversos protótipos de versões híbridas, não tendo, no entanto, atingido a fase de comercialização.

O maior esforço no desenvolvimento e comercialização de veículos híbridos eléctricos foi feito por fabricantes japoneses: em 1997, a Toyota lançou o modelo Prius e a Honda lançou as versões híbridas dos modelos Insight e Civic. Actualmente, estes e outros modelos híbridos entretanto lançados por outros fabricantes -, são comercializados em todo o mundo, apresentando bons desempenhos dinâmicos e níveis de consumo [1], [2]. Quanto ao desenvolvimento dos veículos eléctricos, o maior obstáculo à sua comercialização e difusão reside no estado em que se encontra a tecnologia das baterias. 
Não obstante os progressos e esforços que têm sido feitos no seu desenvolvimento, o desempenho das baterias mais recentes continua aquém das exigências requeridas pelos veículos eléctricos, principalmente, ao nível da densidade de energia (por unidade de peso e volume) e densidade de potência. Atendendo às distâncias relativamente curtas que caracterizam os trajectos nos centros urbanos, será aqui que reside o maior potencial de aceitação destes veículos.

Nas últimas décadas, vários fabricantes de automóveis têm feito alguns investimentos no desenvolvimento da tecnologia das células de combustível, com vista à aplicação em veículos eléctricos. Os maiores desafios ao seu desenvolvimento e proliferação residem na capacidade de produção, armazenamento e distribuição de hidrogénio. A evolução desta tecnologia tem ainda um longo caminho a percorrer, sendo também incerta a opção futura por esta solução.

\section{Classificação e Características dos VH e VE}

As alternativas aos veículos convencionais, baseados em $\mathrm{MCl}$, podem ser classificadas do seguinte modo:

Veículos híbridos (VH) - Em termos gerais, um veículo híbrido é caracterizado por incluir dois ou mais sistemas de propulsão. Os mais usuais são os veículos híbridos eléctricos - combinação de dois sistemas de propulsão: um baseado no $\mathrm{MCl}$, o segundo assente em um ou vários motores eléctricos (ME). Existem várias configurações possíveis para estes veículos: série, paralelo e série-paralelo (esta última com duas variantes);

Veículos eléctricos (VE) - apenas incluem motores eléctricos. Em termos de fontes de energia empregues há a distinguir as baterias das células de combustível.

\subsection{Veículos Híbridos}

A concepção de base dos veiculos híbridos assenta na conjugação das vantagens dos veículos convencionais ( $\mathrm{MCl}$ ) e dos veiculos eléctricos: elevada autonomia e densidades de energia e potência ( $\mathrm{MCl}$ ); elevados rendimentos e emissões nulas a nível local (VE).
Por outro lado, procura-se superar também as limitações de ambos: no caso dos $\mathrm{MCl}$, utilização de grandes quantidades de combustíveis fósseis e emissão de gases de efeito de estufa; para os VE há a referir as autonomias reduzidas, elevados tempos de carregamento do sistema de armazenamento de energia e maior custo inicial [2], [3].

Na utilização de motores eléctricos nos VH há dois objectivos bem vincados: o primeiro é a optimização do rendimento do $\mathrm{MCl}$; a recuperação da energia cinética na frenagem do veículo (armazenada nas baterias) é o segundo objectivo. Este apenas é possível pela presença do(s) motor(es) eléctrico(s).

Existem vários modos de funcionamento possíveis, associados às características dos próprios motores [1]:

- $\mathrm{O} \mathrm{MCl}$ propulsiona integralmente o veículo. Esta situação pode ocorrer quando as baterias estão praticamente descarregadas e a potência disponível no veio do $\mathrm{MCl}$ é integralmente necessária para a tracção; estando as baterias à plena carga, um cenário semelhante ocorre no caso da potência de tracção exigida corresponder a um regime de funcionamento óptimo do $\mathrm{MCl}$;

- Propulsão puramente eléctrica ( $\mathrm{MCl}$ desligado). Justificase para os regimes de funcionamento do $\mathrm{MCl}$ com baixos rendimento (ex., nas baixas velocidades) ou em ambientes com limitações de emissões elevadas;

- Propulsão híbrida ( $\mathrm{MCl}+\mathrm{ME})$, se no esforço de tracção são exigidas elevadas potências (por ex., em subidas e elevadas acelerações);

- Frenagem regenerativa, na qual a energia cinética do veículo é recuperada - o motor funciona agora como gerador - e armazenada nas baterias, podendo ser posteriormente utilizada na tracção do veículo;

- O MCl efectua o carregamento das baterias, havendo diferentes cenários a considerar: veículo imobilizado ou numa descida sem modos de tracção e frenagem nos sistemas de propulsão;

- $\mathrm{O} \mathrm{MCl}$ e o(s) $\mathrm{ME}(\mathrm{s})$ - em modo regenerativo -, carregam simultaneamente as baterias do veículo;

- O MCl propulsiona o veículo, bem como efectua o carregamento das baterias;

- $\mathrm{O} \mathrm{MCl}$ carrega as baterias e estas alimentam o(s) ME(s); 
O elevado número de modos de funcionamento nos veículos híbridos, tornam-os muito flexíveis; no entanto, acresce a complexidade do sistema de propulsão, o que implica a necessidade de sistemas complexos de controlo, bem como o desenvolvimento de sistemas de gestão dos fluxos de energia, capazes de optimizarem a eficiência dos modos de funcionamento anteriores.

Em seguida, descrevem-se as três configurações mencionadas para os $\mathrm{VH}$, as quais se distinguem pelo modo como o $\mathrm{MCl}$ é inserido no sistema de propulsão eléctrica.

Configuração Série - O MCl apenas acciona um gerador que alimenta o ME de tracção do veículo; o gerador também efectua o carregamento das baterias. Em termos de concepção, trata-se de um VE assistido por um $\mathrm{MCl}$ [2] Figura 1.

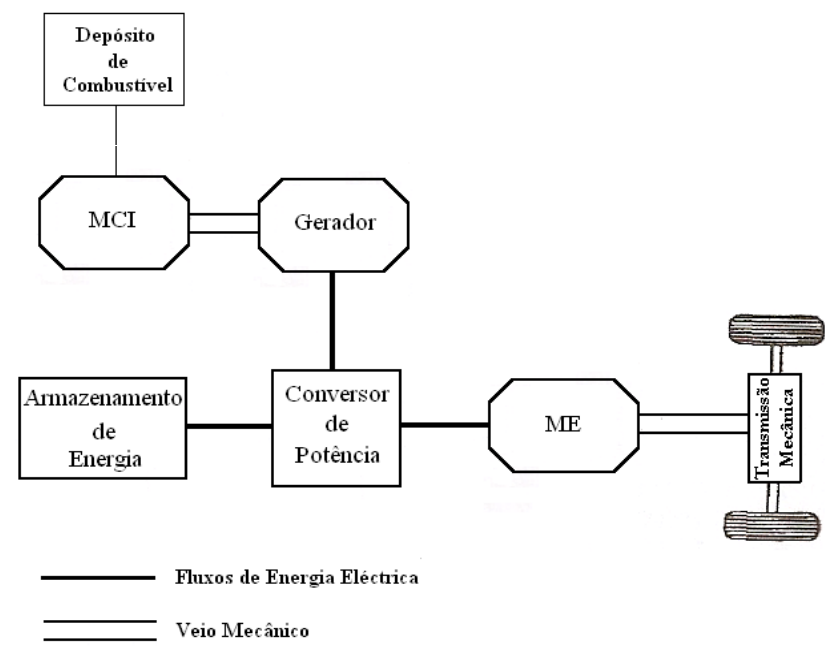

Figura 1 - VH: Configuração Série

Em princípio, podem ser considerados os seguintes modos de funcionamento [1], [2]:

- Energia de propulsão - baterias: o $\mathrm{MCl}$ é desligado, a energia de propulsão provém unicamente das baterias;

- Energia de propulsão - $\mathrm{MCl}$ : a energia de propulsão é somente garantida pelo sistema $\mathrm{MCl} /$ gerador; não há qualquer fluxo de energia nas baterias;

- Energia de propulsão - modo híbrido: a potência de tracção é garantida pelo $\mathrm{MCl}$ e pelas baterias;
- Energia de propulsão/Carregamento das baterias: o sistema $\mathrm{MCl} /$ gerador fornece a energia para propulsionar o veículo e carrega as baterias;

- Frenagem regenerativa: o $\mathrm{MCl}$ é desligado; o $\mathrm{ME}$ funciona como gerador, efectuando o carregamento das baterias;

- Carregamento das baterias: o(s) $M E(s)$ não são alimentados; o sistema $\mathrm{MCl} /$ gerador somente carrega as baterias;

- Carregamento híbrido das baterias: o sistema $\mathrm{MCl} /$ gerador e o(s) $\mathrm{ME}(\mathrm{s})$ - funcionando como gerador(es) - efectuam o carregamento das baterias.

Não existindo ligação mecânica entre o $\mathrm{MCl}$ e o sistema de transmissão de potência, os seus regimes de funcionamento tornam-se mais flexíveis, permitindo optimizar o funcionamento do $\mathrm{MCl}$ (referido anteriormente). No entanto, a existência de três máquinas ( $\mathrm{MCl}$, gerador e $\mathrm{ME}$ ) tornam o sistema de propulsão do veículo mais complexo, normalmente mais pesado e com menores rendimentos em relação às outras configurações.

Configuração Paralela - Existe a possibilidade do $\mathrm{MCl}$ e do ME fornecerem potência, em paralelo, às rodas de tracção do veículo. Conceptualmente, trata-se de um veículo convencional (MCl) com assistência eléctrica (MEs) [2]. Desta forma, ambos os motores estão acoplados ao veio de transmissão através de duas embraiagens independentes, pelo que a propulsão pode ser efectuada pelo $\mathrm{MCl}$, pelo $\mathrm{ME}$ ou por ambos (Figura 2).

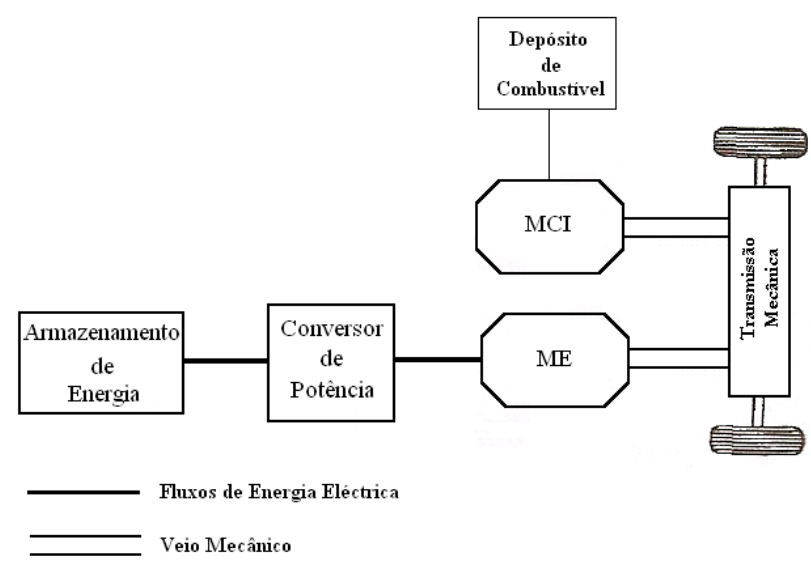

Figura 2 - VH: Configuração Paralela 
Também aqui a optimização do funcionamento do $\mathrm{MCl}$ é conseguida. O motor eléctrico pode funcionar como gerador para carregar as baterias, havendo duas possibilidades:

- Frenagem regenerativa;

- No caso da potência mecânica disponível no veio do $\mathrm{MCl}$ ser superior ao necessário para o esforço de tracção, o excedente é fornecido ao gerador.

Os modos de funcionamento possíveis são os seguintes:

- Propulsão ME: o $\mathrm{MCl}$ é desligado; o veículo é propulsionado apenas pelo $\mathrm{ME}$;

- Propulsão $\mathrm{MCl}$ : o contrário do anterior, o veículo é propulsionado apenas pelo $\mathrm{MCl}$;

- Propulsão Híbrida: ambos os motores ( $\mathrm{MCl}$ e $\mathrm{ME}$ ) contribuem para a propulsão do veículo;

- Propulsão $\mathrm{MCl}$ dividida: uma parte da potência no veio do $\mathrm{MCl}$ é usada na propulsão; a outra parte carrega as baterias, o que implica ter o ME a funcionar como gerador;

- Fenagem simples (apenas regenerativa): o $\mathrm{MCl}$ é desligado; o ME funciona como gerador, efectuando o carregamento das baterias;

- Frenagem regenerativa e mecânica: ME funciona como gerador; $\mathrm{MCl}$ funciona como freio mecânico.

Na configuração paralela há apenas duas máquinas ( $\mathrm{MCl}$ e $\mathrm{ME})$.
Para desempenhos semelhantes é também de referir o uso de $\mathrm{MCl}$ e $\mathrm{ME}$ de menores potências, relativamente à configuração série.

Configuração Série-Paralela - Esta estrutura integra as características das duas anteriores, procurando assimilar as vantagens de ambas. A figura 3 apresenta esta configuração.

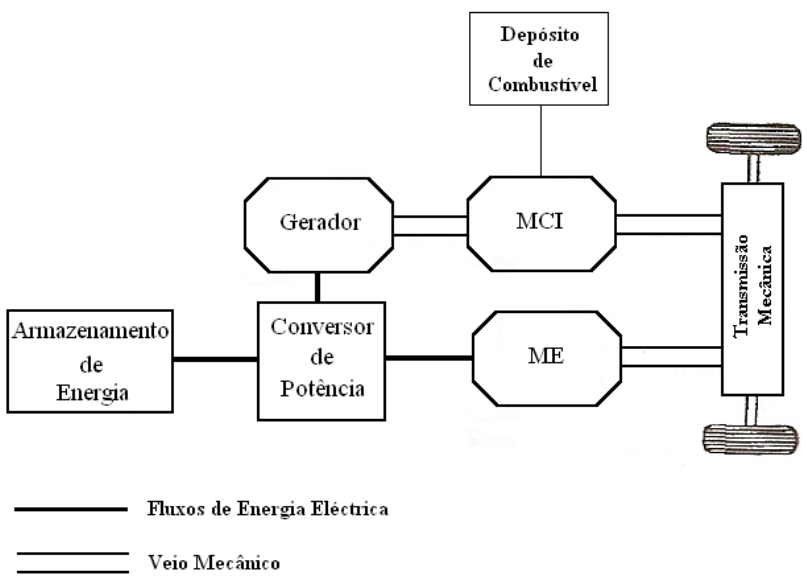

Figura 3 - VH: Configuração Série-Paralela

Em comparação com a estrutura série, há mais uma ligação mecânica ao veio de transmissão; relativamente à estrutura paralela, existe mais uma máquina eléctrica. $\mathrm{O}$ acoplamento mecânico das três máquinas pode ser efectuado através da inclusão de um sistema de engrenagens planetário [1], [4].

A figura 4 ilustra a sua estrutura.

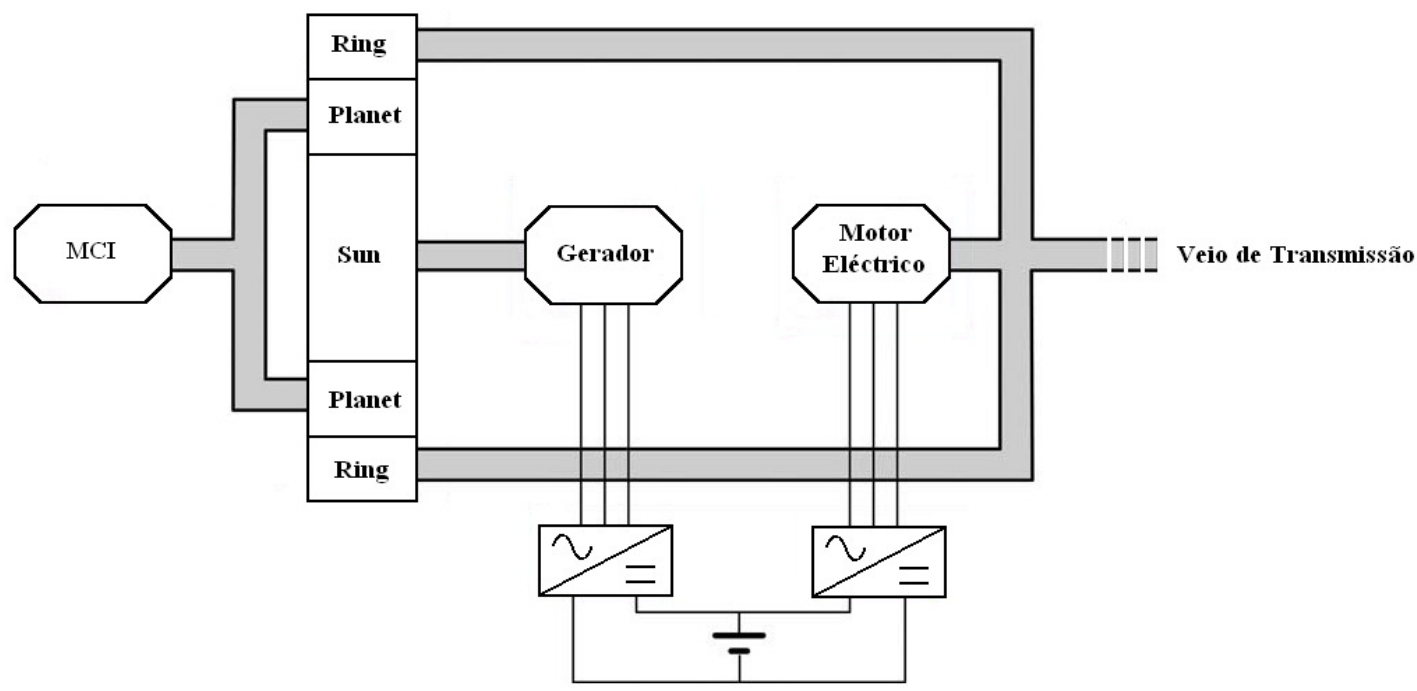

Figura 4 - Sistema de Engrenagens Planetário 
Este sistema tem a vantagem de permitir o funcionamento do $\mathrm{MCl}$ num regime de velocidade constante (permitindo a sua optimização): a variação da velocidade no veio de transmissão do veículo é conseguida através da regulação da potência debitada pelo gerador.

Trata-se, pois, de um sistema de transmissão variável de potência em modo contínuo, mais concretamente, um sistema electrónico de transmissão variável.

Comparativamente aos sistemas puramente mecânicos de transmissão contínua, este sistema electrónico é mais simples, fiável e com melhores rendimentos, uma vez que não existem embraiagens, conversores de binário e caixa de engrenagens.

Com vista ao aumento do rendimento, fiabilidade e robustez, novas concepções de sistemas electrónicos de transmissão foram desenvolvidas, as quais assentam na eliminação do sistema de engrenagens planetário. Nesse sentido refere-se:

- Combinação de duas máquinas eléctricas concêntricas [3];

- Uma única máquina com dois rotores [4], [5].

Configuração Série-Paralela "Complexa” - A configuração representada na figura 5 apresenta semelhanças com a estrutura série-paralela (1 MCl e $2 \mathrm{ME})$.

Há, no entanto, uma diferença importante na máquina eléctrica ligada mecanicamente ao $\mathrm{MCl}$ : a possibilidade de fluxo de energia bidireccional, ou seja, o funcionamento como motor ou gerador.

O potencial e versatilidade desta estrutura são superiores à configuração série-paralela, pois acrescenta um modo de funcionamento com três motores, o qual não existe naquela configuração.

Naturalmente, também o nível de complexidade do(s) sistema(s) de propulsão é grande, o que torna o seu custo mais elevado, juntamente com maiores exigências ao nível do controlo do veículo, bem como do sistema de gestão de energia. Não obstante, é de referir a opção por esta configuração em algumas das séries mais recentes de $\mathrm{VH}$ [1], [2].

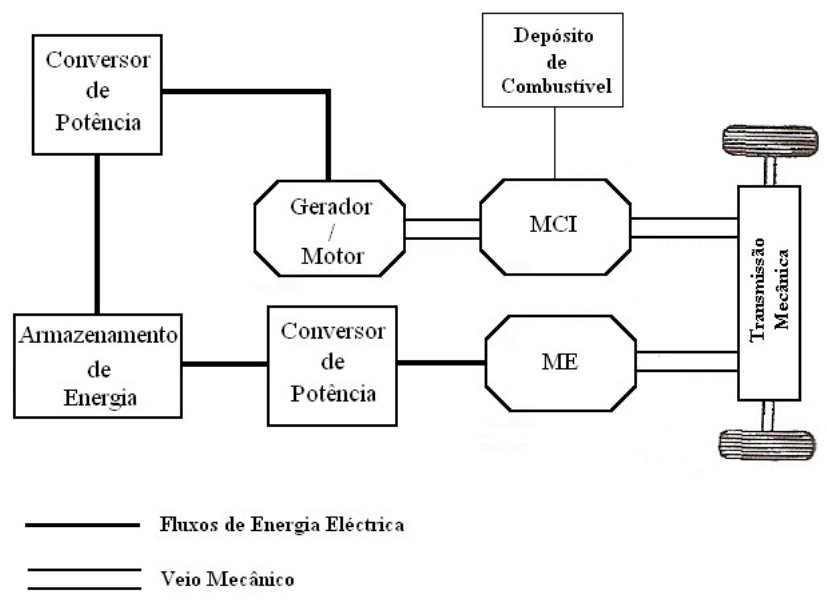

Figura 5 - VH: Configuração Série-Paralela "Complexa"

\subsection{Veículos Eléctricos}

Na figura 6 está representada a estrutura básica deste tipo de veículo [1]

Existem três componentes fundamentais:

- Sistema de propulsão eléctrica;

- Sistema de alimentação/armazenamento de energia;

- Sistema auxiliar.

O sistema de propulsão eléctrica é composto pelos seguintes elementos:

- controlador do veículo

- conversor estático de potência de tracção

- motor eléctrico

- transmissão mecânica

- $\quad$ rodas de tracção.

O sistema de fornecimento/armazenamento de energia inclui os seguintes elementos:

- fonte de energia e/ou sistema de armazenamento de energia

- $\quad$ sistema de gestão de energia

- $\quad$ unidade de reabastecimento.

O sistema auxiliar inclui múltiplas unidades, tais como: a direcção assistida, climatização, etc. 
Trata-se de um sistema comum a qualquer tipo de veículo, seja convencional, híbrido ou eléctrico.

Os sinais emitidos pelos pedais do acelerador e travão (accionados pelo condutor do veículo) são recebidos pelo controlador do veículo, o qual actua no sistema de controlo do conversor de tracção de modo a regular os fluxos de energia entre o motor eléctrico e o sistema de armazenamento de energia. A actuação do controlador do veículo é também função dos sinais recebidos pelo sistema de gestão de energia. São várias as funções deste sistema, sendo de referir o controlo do modo de frenagem regenerativa e respectivo armazenamento de energia, a regulação das operações de reabastecimento e a monitorização dos estados do sistema de armazenamento de energia.
Tal como nos VH, o sistema de gestão de energia é fundamental neste tipo de veículos.

O sistema auxiliar fornece a energia necessária às unidades já referidas (tipicamente com vários níveis de tensão).

Como referido, a estrutura apresentada na figura 6 é elementar.

Existem várias configurações possíveis para o sistema de propulsão dos VE, atendendo à grande flexibilidade de funcionamento dos motores eléctricos. Na figura seguinte são apresentados alguns exemplos, que se julgam ser representativos dessa variedade de configurações [1]. Actualmente, este é um assunto que continua a merecer a atenção de fabricantes e investigadores.

Actuação do Condutor:
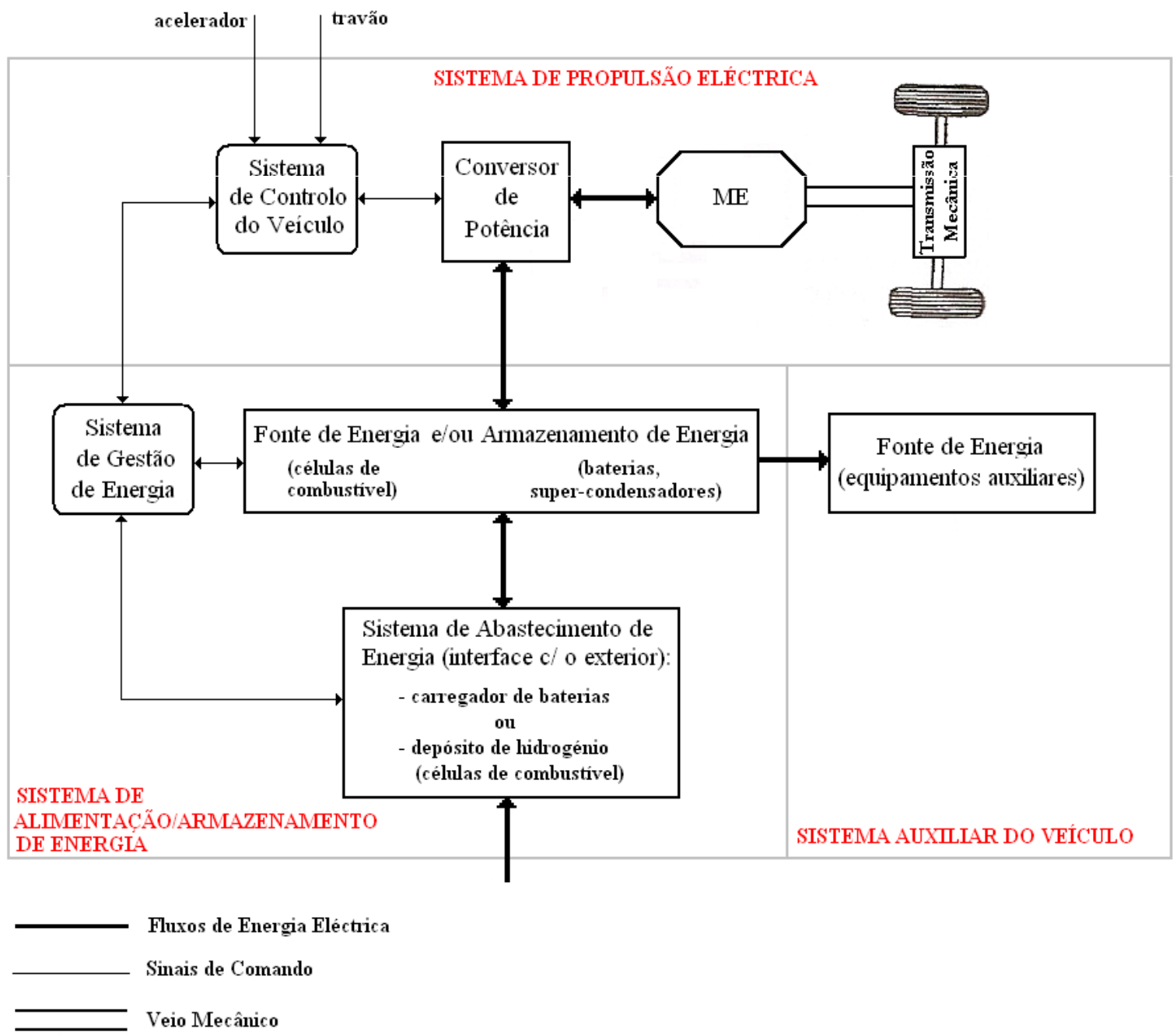

Figura 6 - Configuração Básica de um VE 


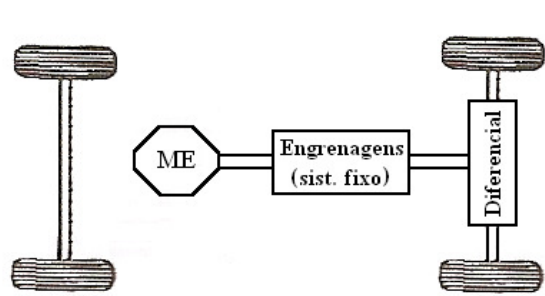

a)

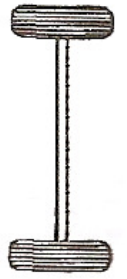

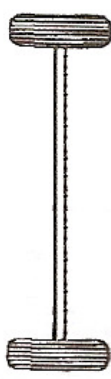

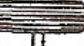

Engren.

(sist. fixo)
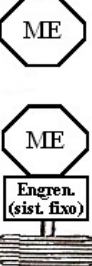

b)

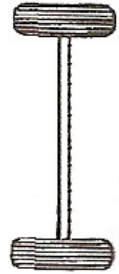

c)

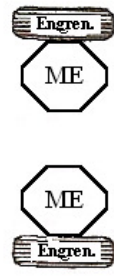

Figura 7 - Sistemas de Propulsão para VE a) Atendendo às zonas possíveis de funcionamento dos motores eléctricos - binário constante (baixas velocidades); potência constante (gama ampla de velocidades) - o sistema habitual de engrenagens com múltiplas relações (várias velocidades) pode ser substituído por um sistema com uma relação fixa. Deste modo, a embraiagem é eliminada, reduzindo o peso e tamanho do sistema de transmissão mecânica; o controlo do sistema de propulsão torna-se mais simples.

b) Nesta configuração, o diferencial mecânico é substituído por dois motores eléctricos. Naturalmente, são os respectivos sistemas de controlo que garantem velocidades distintas em trajectos curvilíneos.

c) Com vista a tornar mais simples o sistema de propulsão, os motores eléctricos são fixados à própria roda de tracção, através de engrenagens (sistema inwheel). Esta concepção coloca desafios vários ao motor (dimensões, peso, robustez, fiabilidade, ...).

d) Relativamente à concepção anterior, é eliminado o sistema de engrenagens: os rotores dos motores são montados directamente nas rodas de tracção, pelo que o controlo da velocidade do veículo corresponde ao controlo directo da velocidade dos motores.
As exigências colocadas a estes motores são várias, nomeadamente, a capacidade de desenvolver elevados binários no arranque. De referir que uma abordagem às tendências actuais dos tipos de motores eléctricos aplicados em VE foi apresentada num artigo anterior.

Neste tipo de veículos, as emissões locais associadas são nulas. Naturalmente, esta afirmação não considera as fontes de energia utilizadas no carregamento das baterias. Com efeito, as emissões globais podem ser consideráveis, dependendo da proveniência da energia armazenada nas baterias.

No momento actual, as principais desvantagens destes veículos residem no elevado peso e custo inicial das baterias, autonomias limitadas, tempos longos de carregamento e densidades de potência reduzidas. Não obstante, nos últimos anos têm sido empreendidos elevados esforços, no meio académico e industrial, com vista ao desenvolvimento de novos tipos de baterias [6], bem como de estruturas híbridas de armazenamento de energia baterias, super-condensadores e flywheels (esta última em menor grau). 
Como foi referido, actualmente há a considerar duas variantes de $V E$, associadas ao tipo de alimentação do veículo. As principais características de ambas são apresentadas a seguir.

\subsubsection{Tipos de Baterias}

Actualmente, as baterias mais usadas nos VE (e também nos VH) são as de chumbo/ácido (PB) convencionais, de hidratos metálicos de níquel (NiMH) e de iões de lítio (Li lon) Particularmente nestas últimas, têm sido obtidos aumentos consideráveis nos valores da densidade de energia (de momento apresentam valores muito superiores aos restantes tipos de baterias). Há uma clara tendência para a sua integração com super-condensadores, aproveitando os elevados valores de densidade de potência destes últimos [3], [7]. Tais sistemas híbridos de armazenamento de energia são mais complexos, necessitando da inclusão de conversores estáticos de potência e de sistemas de gestão de energia específicos. De acordo com [8] há diversas vantagens a considerar nestes sistemas, sendo de realçar o desacoplamento do controlo dos requisitos de energia e potência (esta última é essencial nas frenagens); também a eficiência na gestão de energia do sistema de armazenamento vem melhorada.

Existem diversos factores que condicionam os desempenhos das baterias, dos quais se enumeram alguns dos mais relevantes:

- Nível de carga - State of Charge (SOC);

- Capacidade de armazenamento;

- Tensões e correntes;

- Frequência das cargas e descargas;

- Temperatura de funcionamento;

- Idade da bateria.

As baterias usadas nos veículos de tracção estão sujeitas a ambientes e condições de funcionamento muito agressivos (amplas variações de temperatura, ciclos de carga exigentes, choques e vibrações mecânicas). Estes aspectos podem contribuir para um envelhecimento precoce, traduzido pela diminuição da sua capacidade de armazenamento e aumento da resistência interna. [9]

O sistema de gestão das baterias (Battery Management System) é fundamental, não apenas na monitorização do estado das baterias e sua protecção, mas também para permitir as operações de carga e descarga, em coordenação com o sistema de gestão de energia. $O$ modo de funcionamento em frenagem regenerativa é dos mais críticos a considerar, uma vez que as correntes envolvidas e respectivos gradientes podem destruir as baterias. Em particular, as baterias de lítio exigem condições de funcionamento muito bem controladas, sob pena de se danificarem. Com efeito, são muito sensíveis a sobretensões, sobrecorrentes e à temperatura de funcionamento.

\subsubsection{Células de Combustível}

São dispositivos geradores de energia eléctrica, resultante de reacções electroquímicas baseadas em hidrogénio (combustível não poluente, com elevada densidade de energia). Sublinha-se o facto de se tratar de geradores de energia, enquanto as baterias são armazenadores de energia. Uma característica importante a referir é que o produto das reacções é apenas vapor de água. As principais vantagens residem na elevada eficiência energética das reacções electroquímicas, emissões locais nulas e tempos curtos de abastecimento (depósito de hidrogénio). [2], [3]

A energia eléctrica produzida nas células de combustível é usada na propulsão do veículo ou no carregamento das baterias e super-condensadores para uso futuro.

\section{Alimentação Externa de Energia Eléctrica (Plug-in)}

Estes veículos podem ser ligados a um sistema de carregamento exterior das baterias.

Os veículos híbridos Plug-in têm sistemas de propulsão semelhantes aos híbridos convencionais. Para distâncias curtas, o veículo funciona em modo puramente eléctrico, com as baterias a fornecer a energia necessária à propulsão. 
Nas distâncias longas, quando a carga das baterias é inferior a um valor especificado, o veículo passa a funcionar no modo híbrido. Deste modo, conseguem-se funcionamentos que se aproximam mais dos veículos puramente eléctricos [10].

É de referir que as baterias usadas nos VH Plug-in têm de ter características semelhantes às exigidas para os VE. De modo geral, os VE são sempre do tipo Plug-in.

Os veículos Plug-in poderão também interagir com a rede pública de energia, podendo contribuir para uniformizar o diagrama de cargas: durante o período nocturno (menor procura de energia) efectua-se o carregamento; nas horas diurnas (maior procura de energia), havendo excedente de energia armazenada nos veículos, este pode ser injectado na rede [10], [11].

A Tabela 1 apresenta uma síntese das características dos tipos de veículos considerados.

\section{Conclusões}

Os custos e limitações das reservas de combustíveis fósseis e os impactos ambientais decorrentes da sua utilização intensa, conduziram a um aumento no interesse e desenvolvimento dos veículos eléctricos e híbridos, não apenas por parte da comunidade científica mas também ao nível dos governos e opiniões públicas mundiais.

Até ao momento, os veículos híbridos têm conhecido um maior grau de desenvolvimento, que se reflecte na variedade de modelos comercialmente disponibilizados pelos principais fabricantes e automóveis. Os principais desafios que continuam a ser enfrentados estão no controlo e optimização das diferentes fontes de energia (o que implica desenvolver sistemas de gestão de energia eficazes, com capacidade de actuação em tempo real) e no custo final do veículo.

Tabela 1 - Características de VH e VE [2]

\begin{tabular}{|c|c|c|c|}
\hline & VH & VE (baterias) & VE (cél. de combust.) \\
\hline Sistema de Propulsão & $\begin{array}{c}\text { - Motores eléctricos } \\
-\mathrm{MCl}\end{array}$ & $\begin{array}{l}\text { - Motores } \\
\text { eléctricos }\end{array}$ & - Motores eléctricos \\
\hline $\begin{array}{l}\text { Sistema de Armazenamento } \\
\text { de Energia }\end{array}$ & $\begin{array}{l}\text { - Baterias } \\
\text { - Super-condensadores } \\
\text { - Combustíveis fósseis ou } \\
\text { alternativos }\end{array}$ & $\begin{array}{l}\text { - Baterias } \\
\text { - Super-condensadores }\end{array}$ & $\begin{array}{l}\text { - Depósito de H2 } \\
\text { - Baterias } \\
\text { - Super-condensadores }\end{array}$ \\
\hline $\begin{array}{l}\text { Fontes de Energia e Infra- } \\
\text { estruturas }\end{array}$ & $\begin{array}{l}\text { - Estações de gasolina } \\
\text { - Pontos de carregamento de } \\
\text { energia ("Plug-in” híbrido) }\end{array}$ & $\begin{array}{l}\text { - Pontos de carregamento de } \\
\text { energia ("Plug-in") }\end{array}$ & $\begin{array}{l}\text { - } \mathrm{H} 2 \\
\text {-Produção de } \mathrm{H} 2 \text {; infra- } \\
\text { estruturas de transporte }\end{array}$ \\
\hline Características & $\begin{array}{l}\text { - Emissões locais baixas } \\
\text { - Elevada economia de } \\
\text { combustível } \\
\text { - Dependente de } \\
\text { combustíveis fósseis } \\
\text { - Autonomia longa } \\
\text { - Disponível }\end{array}$ & $\begin{array}{l}\text { - Emissões locais nulas } \\
\text {-Rendimentos elevados } \\
\text {-Não depende directam. de } \\
\text { combustíveis fósseis } \\
\text { - Autonomia limitada } \\
\text { - Disponível }\end{array}$ & $\begin{array}{l}\text { - Emissões locais nulas } \\
\text {-Rendimentos elevados } \\
\text { - Não depende directamente } \\
\text { de combustíveis fósseis } \\
\text { - Em desenvolvimento }\end{array}$ \\
\hline Principais Desvantagens & $\begin{array}{l}\text { - Desempenhos das baterias } \\
\text { - Controlo e optimização de } \\
\text { consumos; gestão de várias } \\
\text { fontes de energia } \\
\text { - Custo superior ao dos } \\
\text { veículos convencionais } \\
\text { (MCl) }\end{array}$ & $\begin{array}{l}\text { - Desempenhos e tempos de } \\
\text { vida útil das baterias } \\
\text { - Disponibilidade de pontos } \\
\text { de carregamento de energia } \\
\text { - Elevado custo inicial }\end{array}$ & $\begin{array}{l}\text { - Custo elevado das células } \\
\text { de combustível, ciclos de } \\
\text { vida curtos, fiabilidade } \\
\text {-Produção de H2; criação de } \\
\text { infra-estruturas de } \\
\text { transporte } \\
\text { - Custo elevado do veículo }\end{array}$ \\
\hline
\end{tabular}


Nos últimos anos, os veículos eléctricos têm vindo a conhecer um maior desenvolvimento dos seus subsistemas, sendo de destacar: novas concepções de máquinas eléctricas e conversores de potência, estruturas híbridas nos sistemas de armazenamento de energia (baterias integradas com super-condensadores e respectivos conversores de potência). O grande obstáculo continua a residir nas características das baterias disponíveis (densidades de energia, ciclos de carga/descarga, custos). Também aqui o desenvolvimento de sistemas de gestão de energia em tempo real será um factor determinante no sucesso destes veículos.

A opção pelas células de combustível é ainda uma incógnita grande: não só a sua tecnologia se encontra numa fase muito inicial, como também esta via implicará a disseminação em larga escala de infra-estruturas para a produção, distribuição e armazenamento de hidrogénio.

A necessidade de integração de múltiplos domínios científicos e tecnológicos, tais como, indústria automóvel, máquinas eléctricas e respectivo controlo, electrónica de potência e sistemas de armazenamento de energia, com desempenhos semelhantes aos dos veículos convencionais $(\mathrm{MCl})$, coloca elevados níveis de exigência à concepção dos VH e VE. Como tal, a modelização e simulação destes sistemas assume um papel determinante no seu desenvolvimento, uma vez que permite a concepção e teste de novas estruturas e sistemas de controlo, sem grandes exigências em termos materiais e de tempo. Também no campo do diagnóstico de avarias é de salientar a mais-valia conseguida com ferramentas de modelização e simulação.

Por último, o futuro dos VH e VE passará seguramente pela integração das opiniões públicas mundiais e respectivos governos com os interesses de múltiplos sectores, tais como, indústria automóvel, transportes, comunidade académica e empresas do ramo energético.

\section{Bibliografia}

[1] Ehsani, Mehrdad, Gao,Yimin, E. Gay, Sebastien, Emadi, Ali (2005). "Modern Electric, Hybrid Electric and Fuel Cell Vehicles Fundamentals, Theory and Design", CRC Press.

[2] Chan, C.C. (2007). "The State of the Art of Electric, Hybrid, and Fuel Cell Vehicles", Proceedings of the IEEE, Vol. 95, No. 4, pp. 704-718.

[3] Chan, C.C. et al. (2010). "Electric, Hybrid and Fuel- Cell Vehicles: Architectures and Modeling", IEEE Transactions on Vehicular Technology, Vol.59, No2, pp. 589-598.

[4] K. T. Chau and C. C. Chan (2007). "Emerging energyefficient technologies for Hybrid Electric Vehicle", Proc. IEEE, vol. 95, no. 4, pp. 821-835.

[5] Hoeijmakers, Martin J., Ferreira, Jan A. (2006). "The Electric Variable Transmission", IEEE Transactions on Industry Applications, Vol.42, No4, pp. 1092-1100.

[6] Affanni, Antonio et al. (2005). "Battery Choice and Management for New-Generation Electric Vehicles", IEEE Transactions on Industrial Electronics, Vol.52, No5, pp. 1343-1349.

[7] Sun, Liqing et al. (2008). "State of Art of Energy System for New Energy Vehicles", IEEE Vehicle Power and Propulsion Conference (VPPC), September 3-5, China.

[8] Miller, John M., Startorelli, Gianni (2010). "Battery and Ultracapacitor Combinations - Where Should the Converter Go?", IEEE Vehicle Power and Propulsion Conference (VPPC), September 1-3, France.

[9] http://www.mpoweruk.com

[10]Amjad, Shaik al. (2010). "Review of Design Considerations and Technological Challenges for Successful Development and Deployment of Plug-in Hybrid Electric Vehicles", Renewable and Sustainable Energy Reviews, No14, pp. 1104-1110, Elsevier.

[11]Somayajula, Deepak et al. (2009). "Designing Efficient Hybrid Electric Vehicles", IEEE Vehicular Technology Magazine, Vol.4, no.2, pp. 65-72. 